\title{
Reliability and validity of a basketball-specific fatigue protocol simulating match load
}

\author{
Karel Hůlka*, Michal Lehnert, and Jan Bělka \\ Faculty of Physical Culture, Palacký University Olomouc, Olomouc, Czech Republic
}

Copyright: (C) 2017 K. Hůlka et al. This is an open access article licensed under the Creative Commons Attribution License (http://creativecommons.org/licenses/by/4.0/).

\begin{abstract}
Background: Research on the amount and type of fatigue caused by match load depends on protocols based on timemotion analysis of match performance in a given sport. The role of these protocols is to accurately simulate specific player match load, which is, contrary to a match, identical for all participants. Objective: The purpose of the study was to determine the reliability and validity using a basketball-specific fatigue protocol simulating player's performance during a basketball match. Methods: The study involved a total of 25 male basketball players (age $17.4 \pm 1.5$ years; body height $185.1 \pm 7.4 \mathrm{~cm}$ and body mass index $22.1 \pm 0.3 \mathrm{~kg} \cdot \mathrm{m}^{-2}$ ) of U17 and U19 categories. The participants performed a specific basketball fatigue protocol twice during 14 days consisting of four periods separated by breaks as in a basketball match. Each period contained a stage with maximum intensity activities followed by a stage of medium intensity and low intensity. During the protocol, heart rate was recorded and time intervals of maximum, medium and low intensity were measured. Results: The relative reliability measurement pointed to high intra-individual stability of the results, when intraclass correlation coefficient varied from .71 to .92. The typical error of measurement showed that the players should be able to repeat the measurement with less than $1.31 \mathrm{~s}(0.82 \%)$ in total time, $0.17 \mathrm{~s}(2.73 \%)$ in sprint time, and $1.32 \%(1.19 \%)$ for percentage of heart rate. The values 1.68 (38.35\%) of Sprint decrement showed very low repeatability. Conclusion: Measurements using a fatigue protocol showed high validity, reliability, and agreement of repeated measures.
\end{abstract}

Keywords: fatigue, high intensity training, match play, training load, team sport

\section{Introduction}

Basketball is a sport which imposes a highly variable load on participants (Hůlka, Cuberek, \& Bělka, 2013). Basketball performance combines maximum intensity activities and medium or low intensity multidirectional movements such as running, dribbling and shuffling at variable velocities and jumping (Apostolidis, Nassis, Bolatoglou, \& Geladas, 2004; Narazaki, Berg, Stergiou, \& Chen, 2009). The low intensity activities provide opportunities for recovery (Krustrup, Mohr, $\&$ Bangsbo, 2002). The frequency of sprint activities, intensity at which they are performed, and length of recovery is influenced by numerous factors such as the level at which the game is being played (Ben Abdelkrim, Chaouachi, Chamari, Chtara, \& Castagna, 2010), players' fitness (Krustrup, Mohr, Ellingsgaard, \& Bangsbo, 2005), playing position (Di Salvo et al., 2007), and

\footnotetext{
* Address for correspondence: Karel Hůlka, Department of Sport, Faculty of Physical Culture, Palacký University Olomouc, třída Míru 117, 77111 Olomouc, Czech Republic. E-mail:karel.hulka@upol.cz
}

the opponents' performance level (Castellano, BlancoVillasenor, \& Alvarez, 2011).

The analysis of work load during basketball matchplay is important from the point of view of performance capacity development and also for injury prevention. Basketball is a typical pivoting sport where the most frequent are lower limb injuries including injuries of the knee joint and hamstrings (Prodromos et al., 2008). There are a number of mechanisms that relate to increased risk of knee and hamstring injury and it has been documented that muscular and neuromuscular control are important in reducing load on ACL and thus reducing the risk of ACL injury (Hawkins, Hulse, Wilkinson, Hodson, \& Gibson, 2001; Oliver \& Smith, 2010). It has been also documented that muscle fatigue is one of the aetiological factors of ACL and hamstring injury (Dai, Mao, Garrett, \& Yu, 2014; Sangnier \& Tourny-Chollet, 2007). Fatigue reduces dynamic knee stability and thus increases risk of ACL injury (Rozzi, Lephart, \& Fu, 1999; Smith et al., 2012; Yu \& Garrett, 2007) and hamstring injury (Sangnier \& Tourny-Chollet, 2007; Small, McNaughton, Greig, \& Lovell, 2010). 
From reasons mentioned above it is clear that players' ability to cope with basketball-specific fatigue experienced during match is crucial both from the point of view of injury prevention. Data on players' external load combined with data on internal response such as heart rate response, sources of muscular energy, muscle recruitment patterns and their alterations, muscle capacity to produce and absorb force etc. are used to provide insight into the demands of team sports (Matthew \& Delextrat, 2009; Woods et al., 2004). This knowledge of modifiable (and also non-modifiable) injury risk factors is required to create appropriate training programmes to improve the player's conditioning preparedness and hence reduce the rate at which he or she fatigues and the stress on the musculoskeletal system (McKeag, 2003).

It has been shown that during a basketball match internal load expressed in terms of mean heart rate is about $87-91 \%$ of peak heart rate (Ben Abdelkrim, El Faaza, \& El Ati, 2007; McInnes, Carlson, Jones, \& McKenna, 1995; Montgomery, Pyne, \& Minanhan, 2010; Ziv \& Lindor, 2009). The external load on players in basketball games has mainly been investigated through time-motion analysis quantifying various low- to high-intensity movement patterns and distance covered (Klusemann, Pyne, Hopkins, \& Drinkwater, 2013). External load expressed as distance covered varies between $4500 \mathrm{~m}$ and $6300 \mathrm{~m}$ (Erčulj et al, 2008; Hůlka et al., 2013; Narazaki et al., 2009). The number of changes of direction and number of accelerations and decelerations vary from 800 to 1050 (Ben Abdelkrim et al., 2007; Klusemann et al., 2013; McInnes et al., 1995), and the number of jumps (one or two leg takeoffs into the air) between 40 to 50 (Ben Abdelkrim et al., 2007). Taylor (2003) showed that during the course of a match a player performs $105 \pm 51$ sprints (efforts at maximal intensity, speed $>5.10 \mathrm{~m} \cdot \mathrm{s}^{-1}$ ). McInnes et al. (1995) showed that players spent $35 \%$ of the game by walking (activity at no greater intensity than walking pace i.e. 0.10 to $1.00 \mathrm{~m} \cdot \mathrm{s}^{-1}$ ) or standing and only $15 \%$ in high intensity running or shuffling.

Research on the amount and type of fatigue caused by match load depends on protocols based on timemotion analysis of match performance in a given sport. The role of these protocols is to accurately simulate specific player match load, which is, contrary to a match, identical for all participants. There are match load protocols for soccer (e.g., Small et al., 2010; Williams, Abt, \& Kilding, 2010) but there is a paucity of basketball-specific protocols. For basketball we found only the Basketball Exercise Simulation Test (BEST; Scanlan, Dascombe, \& Reaburn, 2012). This test simulates one quarter only and we consider that its main purpose is to assess the basketball-specific physical preparedness of players.

Our intention was to construct and verify a basketball-specific fatigue protocol which would mimic the demands of game play as accurately as possible and thus permit inferences about the neuromuscular fatigue induced by match play.

The objective of the study was to assess the reliability, usefulness, and validity of a basketball-specific fatigue protocol simulating player load during a basketball match.

\section{Methods}

\section{Participants}

The research study involved a total of 25 basketball players in the U17 and U19 categories from the Czech Republic (men; age $17.44 \pm 1.52$ years, height $185.10 \pm 7.44 \mathrm{~cm}$, body mass index $22.13 \pm 0.31 \mathrm{~kg} \cdot \mathrm{m}^{-2}$ ). All the players were involved in the second nationwide league (called the $1^{\text {st }}$ league) in the 2014/2015 season and had at least seven-year experience of the game. Players took part in four team sessions (six hours per week), one conditioning session (one hour per week), and one individual training session per week (one hour per week). The study was approved by local ethic committee. Prior to data collection the players were informed about the purpose of the measurements and provided written, informed consent in accordance with the Helsinki Declaration. The involvement of the players was voluntary and the results were used only for the purposes of this research.

\section{Specific basketball fatigue protocol $\left(\mathrm{BSFP}_{28}\right)$}

Data were collected over four separate periods as in a match. There is a two-minute break following the first and third periods and a fifteen-minute break following the second period. Each period consists of seventeen activity sections involving maximal activity (sprints), submaximal activity (running at $3-5 \mathrm{~m} \cdot \mathrm{s}^{-1}$ ), low intensity activity (jogging and walking at $1.5-3 \mathrm{~m} \cdot \mathrm{s}^{-1}$ ) and standing (for $15 \mathrm{~s}$ ). This number of laps was mathematically calculated from time-motion analysis data of a match (Ben Abdelkrim et al., 2007; Klusemann et al., 2013; McInnes et al., 1995) to copy one. Participants were instructed regarding the intensity required in each section and then have to practise maximal (time interval from beginning of the test to $6.5 \mathrm{~s}$ ), submaximal (time interval from 6.5 to $10.5 \mathrm{~s}$ ) and low intensity activities (time interval from 10.5 to $28 \mathrm{~s}$ ). The first maximum intensity section starts when a whistle is blown and time is measured by electronic timing gates (PR1aW, ALGE-TIMING GmbH, Lustenau, Austria) 
with one hundredth of a second accuracy. Times of the remaining two sections are measured manually using stopwatches to verify measurement validity. The starting gate is situated on the semicircle under the basket (1.2 m from the baseline), the width is $1.2 \mathrm{~m}$. The finish gate is situated $2.99 \mathrm{~m}$ from the baseline, one part of the finish gate is on the sideline and the width is $1.2 \mathrm{~m}$ (Figure 1). The player is required to jump to touch the backboard before every other start. A high intensity segment consists of sprinting to a cone placed at the intersection of the three point line and extended free throw line, $5.8 \mathrm{~m}$ from baseline (distance moved $=6.75 \mathrm{~m}$; participants stop when their right foot enters the perimeter lane), followed by high intensity shuffling to the corner of a designated area $(2.8 \mathrm{~m}$; participants stop when their left foot enters the corner of the designated area), then swing high intensity shuffling to the baseline $(5.8 \mathrm{~m}$; participants stop when their right foot crosses the baseline) and finally sprinting to the finish gate $(5.5 \mathrm{~m})$. After the finish gates, the middle intensity segment begins. This consists of running to the half line $(11 \mathrm{~m})$, backpedalling to the opposite baseline $(14 \mathrm{~m})$, and a medium intensity shuffle to the corner of the designed area $(7.3 \mathrm{~m})$. The third - low intensity - segment consists of walking $(27.8 \mathrm{~m})$.

\section{Measurement procedure}

Two weeks before the measurement, the participants took a maximum load field test, the Yo-Yo intermittent level 1 recovery test (Bangsbo, Iaia, \& Krustrup, 2008) to determine peak heart rate $\left(\mathrm{HR}_{\text {peak }}\right)$ using the procedure described by Attene et al. (2014).
All measurement sessions began with a 20-minute warm-up consisting of five minutes of dribbling and passing drill (jogging tempo), ten minutes of dynamic whole body stretches, and brief high-intensity runs with dribbling.

Players participated in a training session during which they learned the movement patterns also the first maximal intensity segment measured by photocells (identified by number 1 on the Figure 1), and practised the pace required in the second and third segments (6.5 to $10.5 \mathrm{~s}$ and to $28 \mathrm{~s}$ respectively; identified by number 2 and 3 on the Figure 1), which corresponds to the speeds specified for medium and low intensity activities by Barbero-Alvarez, Soto, Barbero-Alvarez, and Granda-Vera (2008) and Bishop and Wright (2006). This was followed by two measurement sessions which were used to determine the reliability and validity of the $\mathrm{BSFP}_{28}$. There was a break of 14 days between measurement sessions. Measurement sessions took place on Mondays following a weekend without a match and all sessions took place at the same time under comparable conditions. Prior to each measurement session the players performed their usual warm-up. To provide data on internal player load during the $\mathrm{BSFP}_{28}$ we monitored heart rate during the test using the TEAM Polar ${ }^{2}$ Pro system (Polar Electro, Kempele, Finland).

\section{Statistical data analysis}

Our assessment of reliability was based on the recommendations of Atkinson and Nevill (1998), GonzaloSkok, Tous-Fajardo, Arjol-Serrano, and Mendez-Villanueva (2013), and Hopkins (2000), and used indicators

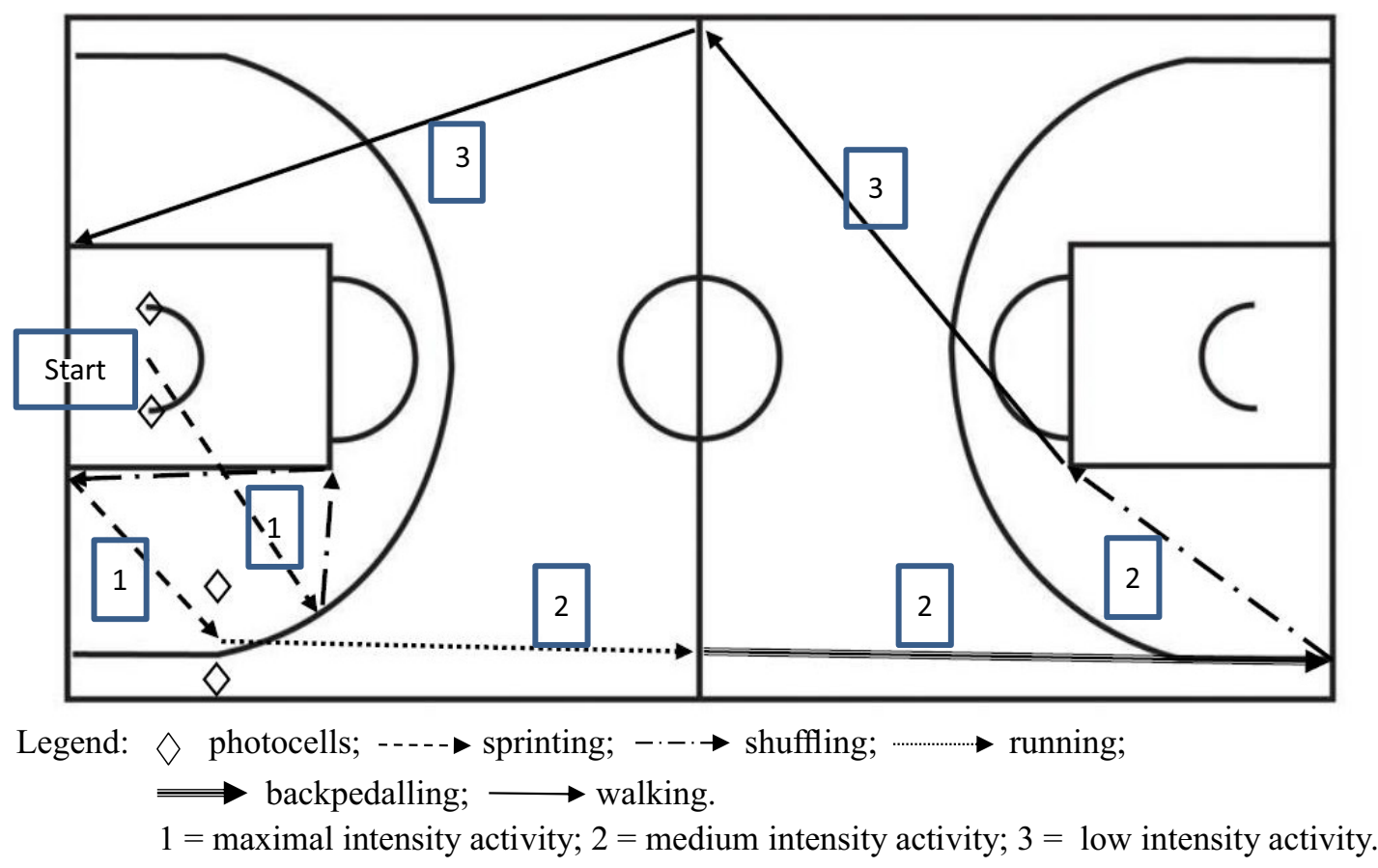

Figure 1. Measured sections of $\mathrm{BSFP}_{28}$. 
of absolute reliability (typical error of measurement and limits of agreement), relative reliability (intraclass coefficient of correlation), and usefulness. For statistical data processing we used the SPSS statistical software (Version 17.0; SPSS Inc., Chicago, IL, USA). To describe player performance in the measured $\mathrm{BSFP}_{28}$ we used descriptive statistics in the form of mean values and standard deviations. Relative reliability was assessed through the intraclass correlation coefficient according to Hopkins (2000). Absolute reliability was expressed by $90 \%$ limits of agreement and standard error of measurement (SEM). It was calculated according to Bland and Altman (1986) as $1.95 \cdot 2^{0.5} \cdot S E M$. The usefulness of the test was assessed while comparing the smallest worthwhile change calculated with typical error of measurement (TEM) according to GonzaloSkok et al. (2013). TEM was calculated as $M S E^{0.5}$, where $M S E$ was a mean square error. Results were calculated at a level of statistical significance of $p<.05$. Logical (or face) validity was determined according to Impellizzeri and Marcora (2010), which is based on the inherent characteristics of the test to which a measure obviously involves the performance being measured. The workload of $\mathrm{BSFP}_{28}$ was compared with workload parameters from a match.

\section{Results}

During the test the participants covered $5504,6 \mathrm{~m}$; calculations imply that during 40 minutes of a game play they would cover $6,880.80 \mathrm{~m}$, and involves a total of 34 jumps (during simulation of 32 minutes of live time of a match), which corresponds to 42.5 jumps during 40 minutes of a match live time. Table 1 shows average time spent in maximal, medium and low intensities during both trials. The participants spent $363.74 \pm 4.95 \mathrm{~s}(352.92 \pm 4.81 \mathrm{~s})$ in maximal intensity activities which represent $17.42 \%$ (17.03\%) of total time, $639.21 \pm 22.17 \mathrm{~s}(656.20 \pm 40.13 \mathrm{~s})$ which represent
$30.55 \%(31.66 \%)$ of total time in medium intensity activities and $1,088.68 \pm 57.32 \mathrm{~s}(1,062.84 \pm 53.05 \mathrm{~s})$ in low intensity activities which represent $52.03 \%$ (51.31\%) of total time. Table 1 shows the percentage of heart rate, total time, and sprint decrement in both trials.

The reliability, expressed by the intraclass correlation coefficient showed a high level of consistency for percentage of heart rate (.922), sprint times (.866), and total time (.851) according to Hopkins (2000). Only moderate level of consistency showed $\mathrm{S}_{\text {dec }}$ (.711).

The evidence of high consistency was supported by high agreement of two trials expressed by limits of agreement for sprint times $\pm 0.11 \mathrm{~s}$, total time $\pm 1.55 \mathrm{~s}$, and percentage of heart rate $\pm 0.99 \%$. On the contrary, $\mathrm{S}_{\mathrm{dec}}$ showed low agreement of $\pm 2.93 \%$. Typical error measurement expressed absolute values of reliability. According to typical error of measurement, players should be able to repeat the measurement with less than $1.31 \mathrm{~s}(0.82 \%)$ in total time, $0.17 \mathrm{~s}(2.73 \%)$ in sprint time, and $1.32 \%(1.19 \%)$ for percentage of heart rate. The values $1.68(38.35 \%)$ of $\mathrm{S}_{\text {dec }}$ showed very low repeatability.

\section{Discussion}

The objective of the study was to assess the reliability, usefulness, and face validity of a basketball fatigue protocol simulating players' load during a basketball match. The reliability of a new performance test should be determined before it is used in practice (Spencer, Bishop, Dawson, \& Goodman, 2005).

Players' load in a match is influenced by numerous factors, for example the level at which the match is played (Ben Abdelkrim et al., 2010), players' fitness (Krustrup et al., 2005), playing position (Di Salvo et al., 2007), the quality of the opponents (Castellano et al., 2011) and previous training (Battaglia, Paoli, Bellafiore, Bianco, \& Palma, 2014). Research on the amount and type of fatigue caused by match load

Table 1

Descriptive statistics of the test $(M \pm S D)$

\begin{tabular}{lrrr}
\hline Indicator & \multicolumn{1}{c}{$1^{\text {st }}$ trial } & \multicolumn{1}{c}{$2^{\text {nd }}$ trial } & Difference \\
\hline Maximal intensity (s) & $5.35 \pm 0.29$ & $5.19 \pm 0.24$ & $0.17 \pm 0.11$ \\
Medium intensity (s) & $9.40 \pm 0.82$ & $9.65 \pm 1.03$ & $0.31 \pm 0.09$ \\
Low intensity (s) & $16.01 \pm 1.28$ & $15.63 \pm 1.32$ & $0.51 \pm 0.15$ \\
$\%$ HR (\%) & $80.90 \pm 2.11$ & $82.03 \pm 2.11$ & $2.05 \pm 1.28$ \\
Total (s) & $363.74 \pm 4.95$ & $352.92 \pm 4.81$ & $9.98 \pm 3.45$ \\
$\% \mathrm{~S}_{\text {dec }}(\%)$ & $6.18 \pm 2.96$ & $4.38 \pm 1.29$ & $1.64 \pm 1.97$ \\
\hline
\end{tabular}

Note. Maximal intensity $=$ maximal intensity activity time; Medium intensity $=$ medium intensity activity time; Low intensity = low intensity activity time; $\% \mathrm{HR}=$ percentage of maximal heart rate; Total $=$ total time of maximal intensity work; $\% \mathrm{~S}_{\mathrm{dec}}=$ decrease in speed. 
requires protocols based on time-movement analysis of match performance in a specific sport. The role of these protocols is to accurately copy specific player match load, which is, contrary to a match, similar for all participants.

By analysing match reports from the top men's league we determined that the mean time for the eight most used players in each team was $28.40 \pm 3.98 \mathrm{~min}$. The BSFP $_{28}$ was designed to simulate player's load during 28 minutes of a match. Fatigue protocols are frequently used in football, but there are far more substitutions during a basketball match than during a football match. All observed values were used to estimate the values that the players would achieve in 40 minutes of a game play to make the results comparable with studies of time-motion analysis of game performance in basketball.

\section{BSFP $_{28}$ measurement validity}

The total distance covered during $\mathrm{BSFP}_{28}$ is close to the upper limit for total distance covered in a match $(6,605.71 \mathrm{~m})$, which was estimated at $6,235 \pm 354 \mathrm{~m}$ (Erčulj et al., 2008) and 5,880.91 $\pm 831.01 \mathrm{~m}$ (Hůlka et al., 2013). The number of jumps per player per match has been estimated variously as $44 \pm 11$ (Ben Abdelkrim et al., 2007) and $17.3 \pm 8.4$ (Narazaki et al., 2009), BSFP $_{28}$ with 42.5 is similar to Ben Abdelkrim et al. (2007).

A very important aspect of time-movement analysis of game performance is the total number of changes of direction, speed or type of locomotion in a match. Following the intermittent nature of game performance, this is the second factor which distinguishes basketball from sports of a cyclic nature. McInnes et al. (1995) stated $997 \pm 183$ changes of direction, speed or type of locomotion per player in men's basketball during a match, Ben Abdelkrim et al. (2007) reported approximately $1,050 \pm 51$ of these changes per player per match, and Klusemann et al. (2013) reported $809 \pm 80$. The $\mathrm{BSFP}_{28}$ involves 971.4 changes of direction, speed or type of locomotion.

A limiting factor for game performance is the player's ability to perform maximum intensity activities repeatedly, throughout the whole match (Glaister, 2008). For training purposes and simulation of player's load during a match, it is of vital importance to know the number of bursts of maximum intensity activity, their quality and the length of the recovery opportunity (time between burst of maximum intensity). According to McInnes et al. (1995) there are $105 \pm 51$ maximal intensity activities in a match; however Ben Abdelkrim et al. (2007) claimed that there are only $55 \pm 11$. This difference can be attributed to differences in the fitness of the players involved in the two studies. The $\mathrm{BSFP}_{28}$, which simulate 32 min of a match involves 68 bursts of maximal intensity activity which corresponds to 97.14 bursts during a 40-minute match. In terms of the changing load patterns, Bishop and Wright (2006) observed a ratio of $1: 3: 4$ (maximum : medium: low movement activity); Ben Abdelkrim et al. (2007), Taylor (2003) and Hůlka et al. (2013) observed $1: 2: 4,1: 3: 6$ and $1: 2: 5$ respectively. During $\mathrm{BSFP}_{28}$ the participants performed maximum intensity activities for $363.74 \pm 4.95 \mathrm{~s}$, medium intensity activities for $639.21 \pm 27.17 \mathrm{~s}$ and low intensity activities for $1,088.68 \pm 57.32 \mathrm{~s}$. These values give a ratio of $1: 1.79: 3.00$. It could be concluded that this test provides a more exacting alternative than the match measurement results quoted above.

The above mentioned implies that $\mathrm{BSFP}_{28}$ meets the requirements for the simulation of external match load. Heart rate monitoring was used during $\mathrm{BSFP}_{28}$ measurement to verify whether the internal organism reaction is similar to match reaction. Ben Abdelkrim et al. (2007) claim mean heart rate of $171 \pm 4$ beats per minute ( $91 \pm 2 \%$ of maximum heart rate), Narazaki et al. (2009) mention $169.3 \pm 4.5$ beats per minute, and Hůlka et al. (2013) observed $167.47 \pm 13.01$ beats per minute. Mean heart rate was $161.89 \pm 3.06$ beats per minute $(80.90 \pm 2.11 \%$ of maximum heart rate) during the first measurement and $163.24 \pm 4.02$ beats per minute $(82.03 \pm 2.11 \%$ of maximum heart rate). The values are somewhat lower compared with other studies. We believe that the main reason is the absence of physical contact with an opponent, absence of ball handling and absence of stress (Narazaki et al., 2009). All these three factors increase player load during a match.

\section{$\mathrm{BSFP}_{28}$ measurement reliability}

The relative reliability, expressed by intraclass correlation coefficient showed high level of consistency in percentage of heart rate. Such evidence showed that repeated internal response of players' metabolism should be stable and, taking into consideration the validity of the results, similar with internal response during match. Equally, the sprint times and total times of the test showed very high level of consistency. We suppose that the measurement was not weighted by error caused by learning effect. Only medium reliability of moderate and low intensity times showed the difficulty of maintaining the tempo of non-maximal speed. With regard to lower necessity of these times, we consider between-individual variability to be satisfactory.

The values of typical error of measurement are very important for practitioners. High absolute reliability was expressed by typical error of measurement in actual units of measurement. The values of typical error in total times $( \pm 1.31 \mathrm{~s})$ and sprint times 
$( \pm 0.17 \mathrm{~s})$ is crucial for coaches to interpret the results of repeated measures before and after training interventions, because measured differences could be caused by error of measurement not by players' improvement. For future application of $\mathrm{BSFP}_{28}$ in training, a crucial aspect is sensitivity expressed by usefulness of maximum intensity activities, which serves as an indicator of the speed and quality of player's recovery during medium and low intensity activities. Wragg, Maxwell, and Doust (2000) quote 2\% inter-individual variation as the acceptable limit for practical applications. Using this criterion the only variable with significantly unsatisfactory absolute reliability was $\mathrm{S}_{\mathrm{dec}}(38.85 \%)$. Gabbett (2010), Spencer et al. (2005), Glaister et al. (2009) and Hůlka, Bělka, Cuberek, and Schneider (2014) reported a similar problem and concluded that $\mathrm{S}_{\mathrm{dec}}$ cannot be recommended as a fatigue indicator in fatigue protocols due to its high variability. We think that the $\mathrm{S}_{\mathrm{dec}}$ index is too sensitive to extreme values of attempts. With regard to high level of reliability, the usefulness should be established before its application in the training or next research. When we compared the smallest valuable change according to Hopkins (2004) with standard error of measurement, the TEM was always lower than usefulness.

As a limit of this study we consider the decreasing of the intensity during each lap, thus interval load but not intermittent load. This fact may influence the metabolic response of players. On the other hand we wanted to make a practically usable test in terms of organisation and utilization in practice and we think more measured high intensity sections could impair the usability of the protocol by coaches.

\section{Conclusions}

In the simulation of the nature and size of external load of players during a match in the $\mathrm{BSFP}_{28}$ fatigue protocol we found that the internal response of the organism to this load is reasonably similar to match load, what indicate $\mathrm{BSFP}_{28}$ to be valid in context of metabolic and biomechanic specificity. Measurements using basketball-specific fatigue protocol showed high reliability and agreement of the results.

\section{Acknowledgments}

This study was supported by a research grant of Palacký University Olomouc (no. FTK_2014_003).

\section{Conflict of interest}

There were no conflicts of interest.

\section{References}

Apostolidis, N., Nassis, G. P., Bolatoglou, T., \& Geladas, N. D. (2004). Physiological and technical characteristics of elite young basketball players. Journal of Sports Medicine and Physical Fitness, 44, 157-163.

Atkinson, G., \& Nevill, A. M. (1998). Statistical methods for assessing measurement error (reliability) in variables relevant to sports medicine. Sports Medicine, 26, 217-238.

Attene, G., Pizzolato, F., Calcagno, G., Ibba, G., Pinna, M., Salernitano, G., \& Padulo, J. (2014). Sprint vs. intermittent training in young female basketball players. Journal of Sports Medicine and Physical Fitness, 54, 154-161.

Bangsbo, J., Iaia, F. M., \& Krustrup, P. (2008). The Yo-Yo intermittent recovery test: A useful tool for evaluation of physical performance in intermittent sports. Sports Medicine, 38, 37-51.

Barbero-Alvarez, J. C., Soto, V. M., Barbero-Alvarez, V., \& Granda-Vera, J. (2008). Match analysis and heart rate of futsal players during competition. Journal of Sport Sciences, 26, 63-73.

Battaglia, G., Paoli, A., Bellafiore, M., Bianco, A., \& Palma, A. J. (2014). Influence of a sport-specific training background on vertical jumping and throwing performance in young female basketball and volleyball players. Sports Medicine and Physical Fitness, 54, 581-587.

Ben Abdelkrim, N., Chaouachi, A., Chamari, K., Chtara, M., \& Castagna, C. (2010). Positional role and competitivelevel differences in elite-level men's basketball players. Journal of Strength and Conditioning Research, 24, 1346-1355.

Ben Abdelkrim, N., El Fazaa, S., \& El Ati, J. (2007). Timemotion analysis and physiological data of elite under-19year-old basketball players during competition. British Journal of Sports and Medicine, 41, 69-75.

Bishop, D. C., \& Wright, C. (2006). A time-motion analysis of professional basketball to determine the relationship between three activity profiles: High, medium and low intensity and the length of the time spent on court. International Journal of Performance Analysis in Sport, 6, 130-139.

Bland, J. M., \& Altman, D. G. (1986). Statistical method of assessing agreement between two methods of clinical measurement. Lancet, 327, 307-310.

Castellano, J., Blanco-Villasenor, A., \& Alvarez, D. (2011). Contextual variables and time-motion analysis in soccer. International Journal of Sports Medicine, 32, 415-421.

Dai, B., Mao, D., Garrett, W. E., \& Yu, B. (2014). Anterior cruciate ligament injuries in soccer: Loading mechanisms, risk factors, and prevention programs. Journal of Sport and Health Science, 3, 299-306.

Di Salvo, V., Baron, R., Tschan, H., Montero, F. J., Bachl, N., \& Pigozzi, F. (2007). Performance characteristics according to playing position in elite soccer. International Journal of Sports Medicine, 28, 222-227.

Erčulj, F., Dežman, B., Vučkovič, G., Perš, J., Perš, M., \& Krtistan, M. (2008). An analysis of basketball players' movements in the Slovenian basketball league play-offs 
using the SAGIT tracking system. Facta Universitatis. Series: Physical Education and Sport, 6, 75-84.

Gabbett, T. J. (2010). The development of a test of repeatedsprint ability for elite women's soccer players. Journal of Strength and Conditioning Research, 24, 1191-1194.

Glaister, M. (2008). Multiple-sprint work: Methodological, physiological, and experimental issues. International Journal of Sports Physiology and Performance, 3, 107-112.

Glaister, M., Hauck, H., Abraham, C. S., Merry, K. L., Beaver, D., Woods, B., \& McInnes, G. (2009). Familiarization, reliability, and comparability of a 40-m maximal shuttle run test. Journal of Sports Science and Medicine, 8, 77-82.

Gonzalo-Skok, O., Tous-Fajardo, J., Arjol-Serrano, J. L., \& Mendez-Villanueva, A. (2013). Determinants, reliability, and usefulness of bench press repeated power ability test in young basketball players. Journal of Strength and Conditioning Research, 28, 126-133.

Hawkins, R. D., Hulse, M. A., Wilkinson, C., Hodson, A., \& Gibson, M. (2001). The association football medical research programme: An audit of injuries in professional football. British Journal of Sports Medicine, 35, 43-47.

Hopkins, W. G. (2000). Measures of reliability in sports medicine and science. Sports Medicine, 30, 1-15.

Hopkins, W. G. (2004). How to interpret changes in an athletic performance test. Sportscience, 8, 1-7.

Hůlka, K., Bělka, J., Cuberek, R., \& Schneider, O. (2014). Reliability of specific on-ice repeated-sprint ability test for ice-hockey players. Acta Gymnica, 44, 69-75.

Hůlka, K., Cuberek, R., \& Bělka, J. (2013). Heart rate and time-motion analyses in top junior players during basketball matches. Acta Universitatis Palackianae Olomucensis. Gymnica, 43(3), 27-35.

Impellizzeri, F. M., \& Marcora, S. M. (2010). Test validation in sport physiology: Lessons learned from clinimetrics. International Journal of Sports Physiology and Performance, 4, 269-277.

Klusemann, M. J., Pyne, D. B., Hopkins, W. G., \& Drinkwater, E. J. (2013). Activity profiles and demands of seasonal and tournament basketball competition. International Journal of Sports Physiology and Performance, 8, 623-629.

Krustrup, P., Mohr, M., \& Bangsbo, J. (2002). Activity profile and physiological demands of top-class soccer assistant refereeing in relation to training status. Journal of Sports Sciences, 20, 861-871.

Krustrup, P., Mohr, M., Ellingsgaard, H., \& Bangsbo, J. (2005). Physical demands during an elite female soccer game: Importance of training status. Medicine \& Science in Sports \& Exercise, 37, 1242-1248.

Matthew, D., \& Delextrat, A. (2009). Heart rate, blood lactate concentration, and time-motion analysis of female basketball players during competition. Journal of Sports Sciences, 27, 813-821.

McInnes, S. E., Carlson, J. S., Jones, C. J., \& McKenna, M. J. (1995). The physiological load imposed on basketball players during competition. Journal of Sports Sciences, 13, 387-397.

McKeag, D. B. (2003). Basketball. Indianapolis, IN: Blackwell Science.

Montgomery, P. G., Pyne, D. B., \& Minahan, C. L. (2010). The physical and physiological demands of basketball training and competition. International Journal of Sports Physiology and Performance, 5, 75-86.

Narazaki, K., Berg, K., Stergiou, N., \& Chen, B. (2009). Physiological demands of competitive basketball. Scandinavian Journal of Medicine and Science in Sports, 19, 425-432.

Oliver, J., \& Smith, P. (2010). Neural control of leg stiffness during hopping in boys and men. Journal of Electromyography and Kinesiology, 20, 973-979.

Prodromos, C. C., Brown, C., Fu, F. H., Georgoulis, A. D., Gobbi, A., Howell, S. M., ... Shelbourne, K. D. (2008). The anterior cruciate ligament: Reconstruction and basic science. Philadelphia, PA: Saunders Elsevier.

Rozzi, S. L., Lephart, S. M., \& Fu, F. H. (1999). Effects of muscular fatigue on knee joint laxity and neuromuscular characteristics of male and female athletes. Journal of Athletic Training, 34, 106-114.

Sangnier, S., \& Tourny-Chollet, C. (2007). Comparison of the decrease in strength between hamstrings and quadriceps during isokinetic fatigue testing in semiprofessional soccer players. International Journal of Sports Medicine, 28, 952-957.

Scanlan, A. T., Dascombe, B. J., \& Reaburn, R. J. (2012). The construct and longitudinal validity of the basketball exercise simulation test. Journal of Strength and Conditioning Research, 26, 523-530.

Small, K., McNaughton, L., Greig, M., \& Lovell, R. (2010). The effects of multidirectional soccer-specific fatigue on markers of hamstring injury risk. Journal of Science \& Medicine in Sport, 13, 120-126.

Smith, H. C., Vacek, P., Johnson, R. J., Slauterbeck, J. R., Hashemi, J., Shultz, S., \& Beynnon, B. D. (2012). Risk factors for anterior cruciate ligament injury: A review of the literature - Part 1: Neuromuscular and anatomic risk. Sports Health, 1, 69-78.

Spencer, M., Bishop, D., Dawson, B., \& Goodman, C. (2005). Physiological and metabolic response of repeatedsprint activities: Specific to field-based team sports. Sports Medicine, 35, 1026-1044.

Taylor, J. (2003). Basketball: Applying time motion data to conditioning. Strength and Conditioning Journal, 25, 57-64.

Williams, J. D., Abt, G., \& Kilding, A. E. (2010). Ball-sport endurance and sprint test $\left(\right.$ BEAST $\left._{90}\right)$ : Validity and reliability of a 90-minute soccer performance test. Journal of Strength and Conditioning Research, 24, 3209-3218.

Woods, C., Hawkins, R. D., Maltby, S., Hulse, M., Thomas, A., \& Hodson, A. (2004). The Football Association Medical Research Programme: An audit of injuries in professional football - analysis of hamstring injuries. British Journal of Sports Medicine, 38, 36-41.

Wragg, C. B., Maxwell, N. S., \& Doust, J. H. (2000). Evaluation of the reliability and validity of a soccer-specific field test of repeated sprint ability. European Journal of Applied Physiology, 83, 77-83.

Yu, B., \& Garrett, W. E (2007). Mechanisms of non-contact ACL injuries. British Journal of Sports Medicine, 41, 147-151.

Ziv, G., \& Lindor, R. (2009). Physical attributes, physiological characteristics, on-court performances and nutritional strategies of female and male basketball players. Sports Medicine, 39, 547-568. 